\title{
Substance abuse and its psychiatric effect on adolescence
}

\author{
Badr Alghamdi ${ }^{1 *}$, Mohammed Zrari $^{2}$, Alaa Elahi ${ }^{3}$, Meshari Alwagdani ${ }^{4}$, Eman Alghamdi ${ }^{5}$, \\ Hashem Moafa ${ }^{6}$, Shaher Miran ${ }^{6}$, Shahad Alamoudi ${ }^{7}$, Khaled Alshahrani ${ }^{8}$, \\ Mohammed Binnwejim?, Marwan Jaafari ${ }^{10}$
}

\begin{abstract}
Department of Psychiatry, ${ }^{1}$ Mental Health Hospital, Baljurashi, ${ }^{2}$ Al Amal Complex, Medina, ${ }^{3}$ Al Amal Complex, Jeddah, ${ }^{4}$ King Abdullah Medical Complex, Jeddah, Saudi Arabia

${ }^{5}$ Department of Pediatric, King Fahad Specialist Hospital, Dammam, Saudi Arabia

College of Medicine, ${ }^{6} \mathrm{Umm}$ Al-Qura University, Mecca, ${ }^{7}$ Ibn Sina National College, Jeddah, ${ }^{8}$ King Abdulaziz University, Rabigh, ${ }^{9}$ Imam Muhammad ibn Saud Islamic University, Riyadh, ${ }^{10}$ Prince Sattam Bin Abdulaziz University, Al-Kharj, Saudi Arabia
\end{abstract}

Received: 14 May 2018

Accepted: 30 May 2018

\section{*Correspondence:}

Dr. Badr Alghamdi,

E-mail: dr.badr20013@gmail.com

Copyright: () the author(s), publisher and licensee Medip Academy. This is an open-access article distributed under the terms of the Creative Commons Attribution Non-Commercial License, which permits unrestricted non-commercial use, distribution, and reproduction in any medium, provided the original work is properly cited.

\begin{abstract}
Substance abuse amongst adolescence is a widespread health issue that witnesses a progressive increase over years. Substance abuse among this age group is associated with significant psychiatric morbidities that differ according to the substance used. Many literature studies were conducted to explore the psychiatric conditions and consequences associated with substance abuse. To date, cannabis was the most common substance studied and the most well-known illicit drug to be associated with various psychiatric co-morbidities. Other studied substances include alcohol, opiates, barbiturates, hallucinogens, and inhalants. The psychiatric effects of various substances depend on the state, the duration, and the dose of their use. This article will review and discuss the short-term and long-term effects of these substances on the mental health among adolescence.
\end{abstract}

Keywords: Adolescence, Psychiatric effects, Substance abuse

\section{INTRODUCTION}

Substance abuse amongst adolescence is a widespread health issue that witnesses a progressive increase over years. $^{1-3}$ Substance abuse among this age group is associated with significant psychiatric conditions. The actual nature of this association is not yet established i.e. a causal-effect relationship is not clear. It is not well explained whether substance abuse leads to the associated psychiatric effects or the psychiatric disturbances precede and predispose to substance abuse.

Many literature studies were conducted to explore the psychiatric conditions and consequences associated with substance abuse. To date, cannabis was the most common substance studied and the most well-known illicit drug to be associated with various psychiatric co-morbidities. Other studied substances include alcohol, opiates, barbiturates, and hallucinogens. This article will review and discuss the short-term and long-term effects of different substances on the mental health among adolescence.

\section{PSYCHIATRIC EFFECTS OF CANNABIS USE}

Cannabis is a widely used substance among adolescence worldwide. It is the most extensively studied substance in literature researches, and therefore, it is the substance with the most solid and consistent evidence on its psychiatric sequalae. Cannabis abuse was significantly associated with various mental and psychological disturbances. ${ }^{4}$ However, a causal relationship is often not 
clear. Some studies tried to exclude the presence of psychological disturbances and psychiatric diseases before the onset of cannabis abuse to be able to attribute the evolving psychological malalignments to cannabis. Nevertheless, subclinical psychological disturbances might have been there preceding the abuse and they got evident after cannabis use. Pre-existing psychiatric disturbance could also be a risk factor for developing substance use, for instance, depressed patients might be more likely to start substance abuse to get over their depression. ${ }^{5}$ On the other hand, cannabis abuse itself can exacerbate the already existing psychiatric disturbances and flare the subthreshold vulnerability of the individuals to psychological conditions. ${ }^{6,7}$ Researchers have long argued the causal relationship between cannabis and many psychiatric conditions. For example, cannabis was found to be significantly correlated with schizophrenia with a relative risk of 4 to $5 .^{8,9}$ If Cannabis was a cause for schizophrenia, it would be expected that the prevalence of schizophrenia would have increased in a pattern parallel to the increase in cannabis abuse, but because this was not the case, a direct causal-effect relationship between cannabis and schizophrenia cannot be assumed. ${ }^{8,10-12}$

\section{Depression and anxiety}

Cannabis was found to be significantly correlated with many psychiatric conditions. It is positively correlated with depression, anxiety, and psychosis. Schizophrenia was also found to be considerably correlated with cannabis use. As regards the depression, Fergusson et al., in their report about the short-term effects of cannabis use, noted a significant increase in depression and suicidal ideation among adolescence below the age of 15 years using cannabis. ${ }^{13}$ Horwood et al reported similar data amongst young adults. ${ }^{14}$ Brook et al reported a significant correlation between suicidal ideation and cannabis use with an Odd's ratio of $1.13 .{ }^{15}$ This was reported to be significantly higher among males in comparison to females in one study, and the reverse was reported in other studies. ${ }^{16-18}$

\section{Psychosis and schizophrenia}

Cannabis was also notably associated with psychosis, schizophrenic symptoms, and schizophrenia. Andreasen et al, in their study on Swedish military conscripts using cannabis, reported that cannabis use was significantly associated with subsequent diagnosis of schizophrenia with a follow-up period of 15 years, the crude relative risk of this association ranged from 4.0 to $8.9 .^{8}$

Similarly, Arseneault et al, in their prospective study, reported that the use of cannabis at the age of 15 is significantly correlated with the development of schizophrenic symptoms at the age of 26 (Odds ratio 4.5). ${ }^{9}$ Van et al had also noted a significant correlation between cannabis use amongst Dutch adolescence and the development of psychosis. ${ }^{19}$

\section{Antisocial behavior}

Cannabis use among adolescence and young adults was associated with antisocial behavior such as violence, offending, conduct, and crimes. Fergusson et al found that cannabis use at the age of 15 years or before was significantly correlated with conduct disorder (Odds ratio 7.0), crimes and police contact (Odds ratio 4.8), and offending (Odds ratio 5.7). ${ }^{13}$ Similarly, Horwood et al reported a positive correlation between cannabis use at the age of 15 to 21 years and violent crimes (adjusted risk ratio 3.7$){ }^{20}$

The effects of cannabis on various psychiatric conditions may be attributed to its effects on neurotransmitters and hormones. ${ }^{21,22}$ It can be consumed in multiple methods, but the most common method of abuse is through smoking with tobacco cigarettes. ${ }^{23}$ Environmental factors may play a role in cannabis use such as availability of the substance, easy access to sellers, and low educational level. $^{24}$

\section{PSYCHIATRIC EFFECTS OF ALCOHOL ABUSE}

Alcohol is another common substance of abuse used among adolescents, and it has a considerable negative impact on psychiatric health. Alcohol consumption alters the neurotransmitter release and hormonal functions in the central nervous system resulting in various mental disturbances. $^{25}$ Alcohol was reported to be associated with mood and anxiety disorders, psychosis, and many other psychiatric conditions. The wide range of psychiatric disorders associated with alcohol use depends largely on the amount and duration of consumption. It also depends on whether the patient is in a state of acute intoxication, acute withdrawal, or chronic use. ${ }^{26}$

\section{Acute alcohol intoxication}

Acute alcohol intoxication results in initial euphoria followed by irritability, nervousness, and depression. The euphoria is often associated with impaired judgement, slurred speech, ataxia, and regressive central nervous system depression up to coma. Alcohol use was also found to be associated with disinhibiting properties leading to poor judgmental abilities, antisocial aggressive behavior, and loss of impulse inhibition control. ${ }^{27}$ Certain types of alcohol intoxication such as the methanol are associated with visual disturbances and visual loss. ${ }^{28}$ If not properly managed, acute alcohol intoxication will progress to cardiopulmonary depression and renal failure within 48 hours. $^{27}$

\section{Acute alcohol withdrawal}

Acute alcohol withdrawal leads to severe anxiety, panic attacks, and suicidal ideation. It also results in irritability, sweating, nausea, vomiting, and hallucinations. ${ }^{26}$ 


\section{Chronic alcohol use}

Chronic use, on the other hand, is often associated with depression and anxiety. It also predisposes patients to thiamine deletion leading to Wernicke's encephalopathy and Korsakoff's psychosis. Wernicke's encephalopathy consists of a triad of confusion, ataxia, and ophthalmoplegia. If not properly treated, it will result in psychosis and confabulation known as Korsakoff's psychosis. $^{25}$ Chronic alcohol uses also lead to memory and concentration problems, sedation and fatigue, blackouts, and episodes of amnesia, irritability, and suicidal ideation.

\section{PSYCHIATRIC EFFECTS OF BARBITURATES ABUSE}

Barbiturates are another central nervous system depressant that have closely similar effects to alcohol. They are clinically prescribed as hypnotics to induce sleep with phenobarbital being the prototype. Adolescents abuse barbiturates for the initial euphoric and pleasure effect the substance cause with higher doses. Doses of barbiturates that may result in significant toxic effects are ten times the dose used for hypnosis. Acute barbiturates intoxication resembles acute alcohol intoxication. It results in an initial euphoria followed by sedation, ataxia, and slurred speech. It also leads to blackouts and amnesia. In cases of severe intoxication, cardiorespiratory depression evolves leading to coma. ${ }^{29}$

Barbiturates on long-term use have a negative impact on various domain of cognitive functions. They result in poor judgmental abilities, drowsiness, confusion, mood swings, and slowing of mental processing speed. Barbiturates use was also reported to increase the suicidal ideation and suicidal attempts. ${ }^{30}$

\section{PSYCHIATRIC EFFECTS OF OPIATES ABUSE}

Opiates, such as heroin and codeine, are central nervous system depressants that are used clinically as strong pain killers. They can be sniffed, smoked, inhaled, or injected either subcutaneously or intravenously. In higher doses, they result in euphoria which makes them highly potential for abuse. ${ }^{31}$

\section{Acute opiates toxicity}

The psychiatric effects of opiates depend on the state of intake. Acute opiates intoxication results in euphoria, dysphoria, and hallucinations. This is always accompanied with pruritus, dry mouth, urine retention, and gastrointestinal upset. $^{32}$ Overdose of opiates will eventually result in cardiorespiratory depression manifesting as hypothermia, hypotension, respiratory depression, coma, and rarely seizures.

\section{Acute opiates withdrawal}

Acute opiates withdrawal manifestations appear a couple of hours after the last dose of opiates intake. In cases of heroin or morphine use, the first manifestation of withdrawal may take from 6 to 9 hours to appear. Methadone withdrawal manifestations occur later after 12 to 24 hours of last dose. Drug craving is always the first symptom of withdrawal. It is associated with restlessness, irritability, and autonomic dysfunction such as lacrimation, rhinorrhea, and excessive sweating. Later on, gastrointestinal upset, nausea, diarrhea, abdominal cramps, and piloerection occur. ${ }^{31}$

\section{Chronic use}

Chronic use of opiates results in initial euphoria followed by apathy. It also leads to inattention, slow mental processing, memory disturbance, and drowsiness. Patients abusing opiates are often described as "being on the nod" due to the drowsiness they experience the slow mental function they own, and the slow and ataxic movements. $^{31}$

\section{PSYCHIATRIC EFFECTS OF HALLUCINOGENS ABUSE}

Hallucinogens are brain stimulants that are commonly abused amongst adolescents and young adults. They include Lysergic Acid Diethylamide (LSD), Ecstasy, psilocybin, and peyote. As their name indicates, hallucinogens result in frank hallucinations and delusions. They stimulate the central nervous system leading to euphoria, increased alertness, reduced fatigue, increased performance, and decreased appetite. They result in paranoia, violence, hallucinations, and delusions. Physically, the have a stimulant effect on sympathetic and cardiorespiratory systems resulting in pupillary dilatation, palpitation, tachycardia, tachypnea, and hypertension. However, in severe cases, they result in dehydration, hyperthermia, rhabdomyolysis, myocardial infarction, acute ischemic and hemorrhagic strokes, hyperkinetic movement disorders, encephalopathy, and seizures. $^{33}$

With chronic intake, hallucinogens result in persistent psychosis and hallucinogen persisting perception disorder. Persistent psychotic symptoms include paranoia, visual hallucinations, and disorganized thoughts that characteristically do not resolve after the intoxication wears off. Hallucinogen persisting perception disorder refers to the condition in which patients re-experience the same symptoms they used to experience with hallucinogen intake (e.g., visual hallucinations, flashbacks, delusions) without intake of the substance. This disorder is probably attributed to the long-term impact of hallucinogens on hormonal release, serotonin receptors, white matter in the brain, and impulse conduction across central nervous system neuronal axes. $^{34}$ 


\section{CONCLUSION}

Substance use is common amongst adolescence and the prevalence is increasing. Cannabis is the most common and widely abused and subsequently studied substance among this age group. It is associated with various psychiatric disturbances such as depression, anxiety, psychosis, schizophrenia, and antisocial behavior. Alcohol and barbiturates are central nervous system depressants that have closely similar psychiatric effects. Their acute intoxication results in initial euphoria followed by depression, their acute withdrawal is associated with anxiety and panic attacks, and their chronic use leads to depression and psychosis. Opiates acute toxicity causes euphoria and hallucinations, whilst their withdrawal is associated with craving, restlessness, and irritability. Hallucinogens result initially in paranoia, violence, hallucinations, and delusions, whereas on the long-term they lead to persistent psychosis and hallucinogens persistent perception disorder.

\section{Funding: No funding sources \\ Conflict of interest: None declared \\ Ethical approval: Not required}

\section{REFERENCES}

1. Measham F, Wood DM, Dargan PI, Moore K. The rise in legal highs: Prevalence and patterns in the use of illegal drugs and first- and second-generation "legal highs" in South London gay dance clubs. J Subst Use. 2011;16(4):263-72.

2. May PA. Substance abuse and American Indians: Prevalence and susceptibility. Subst Use Misuse. 1982;17(7):1185-209.

3. Vazan P, Golub A, Bennett AS. Substance use and other mental health disorders among veterans returning to the inner city: Prevalence, correlates, and rates of unmet treatment need. Subst Use Misuse. 2013;48(10):880-93.

4. Beer MD. Cannabis and mental health. J Psychiatr Intensive Care. 2007;3(1):45-7.

5. Lipkus IM, Barefoot JC, Williams RB, Siegler IC. Personality Measures as Predictors of Smoking Initiation and Cessation in the UNC Alumni Heart Study. Heal Psychol. 1994;13(2):149-55.

6. Castaneto MS, Gorelick DA, Desrosiers NA, Hartman RL, Pirard S, Huestis MA. Synthetic cannabinoids: Epidemiology, pharmacodynamics, and clinical implications. Drug Alcohol Depend. 2014;144:12-41.

7. Macleod J, Hickman M, Smith GD. Early Exposure to Marijuana and Risk of Later Drug Use Early Exposure to Marijuana and Risk of Later Drug Use. JAMA. 2003;290(3):329.

8. Andréasson S, Engström A, Allebeck P, Rydberg U. Cannabis and Schizophrenia A Longitudinal Study of Swedish Conscripts. Lancet. 1987;330(8574):1483-6.
9. Arseneault L, Cannon M, Poulton R, Murray R, Caspi A, Moffitt TE. Cannabis use in adolescence and risk for adult psychosis: longitudinal prospective study. BMJ. 2002;325(7374):1212-3.

10. Jablensky A, Sartorius N, Ernberg G, Anker M, Korten A, Cooper JE, et al. Schizophrenia Manifestations, Incidence and Course in Different Cultures - a World-Health-Organization 10-Country Study. Psychol Med Monogr Suppl. 1992;20:1-97.

11. Jablensky A. Epidemiology of schizophrenia: The global burden of disease and disability. Eur Arch Psychiatry Clin Neurosci. 2000;250(6):274-85.

12. Lynskey M, Lukas SE, Kranzler HR, Ciraulo DA, Kranzler HR (Ed.., Ciraulo DA (Ed.. Cannabis. Clin Man Addict Psychopharmacol. 2005: 163-181.

13. Fergusson DM, Lynskey MT, Horwood LJ. The short-term consequences of early onset cannabis use. J Abnorm Child Psychol. 1996;24(4):499-512.

14. Fergusson DM, Horwood LJ. Early onset cannabis use and psychosocial adjustment in young adults. Addiction. 1997;92(3):279-96.

15. Brook JS, Cohen P, Brook DW. Longitudinal study of co-occurring psychiatric disorders and substance use. J Am Acad Child Adolesc Psychiatry. 1998;37(3):322-330.

16. McGee R, Williams S, Poulton R, Moffitt T. A longitudinal study of cannabis use and mental health from adolescence to early adulthood. Addiction. 2000;95(4):491-503.

17. Patton GC, Harris R, Carlin JB, et al. Adolescent suicidal behaviours: a population-based study of risk. Psychol Med. 1997;27(3):715-24.

18. Patton GC, Coffey C, Carlin JB, Degenhardt L, Lynskey M, Hall W. Cannabis use and mental health in young people: cohort study. BMJ. 2002;325(7374):1195-8.

19. Van Os J, Bak M, Hanssen M, Bijl RV, De Graaf R, Verdoux H. Cannabis use and psychosis: A longitudinal population-based study. Am J Epidemiol. 2002;156(4):319-27.

20. Fergusson DM, Horwood LJ, Swain-Campbell N. Cannabis use and psychosocial adjustment in adolescence and young adulthood. Addiction. 2002;97(9):1123-35.

21. Grayson M. Cannabis. Nature. 2015;525(7570):S1.

22. Kumra S. Schizophrenia and cannabis use. Minn Med. 2007;90(1):36-8.

23. Mariani JJ, Levin FR. Cannabis. In: Clinical Manual of Addiction Psychopharmacology (2nd Ed.).; 2014: 137-170.

24. Lynskey M, Hall W. The effects of adolescent cannabis use on educational attainment: A review. Addiction. 2000;95(11):1621-30.

25. Healey JC, Winder DG, Kash TL. Chronic ethanol exposure leads to divergent control of dopaminergic synapses in distinct target regions. Alcohol. 2008;42(3):179-90.

26. National Institute on Alcohol Abuse and Alcoholism. Health risks and benefits of alcohol 
consumption. J Natl Inst Alcohol Abus Alcohol. 2000;24(1):5-11.

27. Vonghia L, Leggio L, Ferrulli A, Bertini M, Gasbarrini G, Addolorato G. Acute alcohol intoxication. Eur J Intern Med. 2008;19(8):561-7.

28. Huang B. Methanol intoxication. In: Brain Imaging with MRI and CT: An Image Pattern Approach; 2010: 11-12.

29. Nobay F, Acquisto NM. Barbiturates. In: Wexler, P. (Ed.). Encyclopedia of Toxicology. 3rd edition. Vol 1. Elsevier Inc., Academic Press; 2014; 363-367.

30. Grasso I, Distefano A, Azzolina R. Barbiturates poisoning. Acta Medica Mediterr. 2003;19(3):18990.

31. Cruz SL, Granados-Soto V. Opioids and opiates: Pharmacology, abuse, and addiction. In: Neuroscience in the 21st Century: From Basic to Clinical, Second Edition. 2016: 3625-3657.
32. Lichtermann D, Franke P, Maier W, Rao ML. Pharmacogenomics and addiction to opiates. Eur $\mathbf{J}$ Pharmacol. 2000;410(2-3):269-79.

33. Warsi M, Marcil W, Petty F. Hallucinogen abuse. In: XPharm: The Comprehensive Pharmacology Reference. 2011: 1-7.

34. Hermle L, Simon M, Ruchsow M, Geppert M. Hallucinogen-persisting perception disorder. Ther Adv Psychopharmacol. 2012;2(5):199-205.

Cite this article as: Alghamdi B, Zrari M, Elahi A, Alwagdani M, Alghamdi E, Moafa H, et al.

Substance abuse and its psychiatric effect on adolescence. Int J Community Med Public Health 2018;5:2642-6 